\title{
A Review on Prevalence and Causes of Peripheral Neuropathy and Treatment of Different Etiologic Subgroups with Neurotropic B Vitamins
}

\author{
Hakim $\mathrm{M}^{1^{*}}$, Kurniani $\mathrm{N}^{2}$, Pinzon $\mathrm{R}^{3}$, Tugasworo $\mathrm{D}^{4}$, Basuki $\mathrm{M}^{5}$, Haddani $\mathrm{H}^{6}$, Pambudi $\mathrm{P}^{7,8}$, Fithrie $\mathrm{A}^{9,10}$, \\ Wuysang $\mathrm{AD}^{11}$
}

${ }^{1}$ Department of Neurology, Clinical Neurophysiology and Neuromuscular Disorder Division, Universitas IndonesiaCiptoMangunkusumo National General Hospital, Jakarta, Indonesia; ${ }^{2}$ Department of Neurology, Faculty of Medicine, University of Padjadjaran, Hasan Sadikin Hospital, Jawa Barat, Indonesia; ${ }^{3}$ Department of Neurology, Duta Wacana Christian University School of Medicine, Yogyakarta, Indonesia; ${ }^{4}$ Department of Human Resources and Education, Dr. Kariadi General Hospital, Jawa Tengah, Indonesia; ${ }^{5}$ Department of Neurology Study Program, Faculty of Medicine, Airlangga University, University in Surabaya, Indonesia; ${ }^{6}$ Chairman of PERDOSSI (Indonesian Association of Neurologists) Palembang Chapter, Indonesia; ${ }^{7}$ Department of Medical Faculty, Lambung Mangkurat Banjarmasin University, Indonesia, ${ }^{8}$ Department of Neurology, Ulin General Hospital, Banjarmasin, Indonesia; ${ }^{9}$ Department of Medical Faculty, University of Sumatera, Utara, Indonesia; ${ }^{10}$ Department of Neurology, Head of Neurophysiology Division, University of Sumatera, Indonesia; ${ }^{11}$ Department of Neurology, Hasanuddin University, Sulawesi Selatan, Indonesia

\begin{abstract}
Peripheral neuropathy (PN) is the most common disorder of the peripheral nervous system in adults, and its prevalence increases with age. Because PN is often poorly documented and strongly underdiagnosed, estimating its prevalence in the general population is difficult. Only few epidemiological studies on the prevalence of PN in the general population are available, mostly from industrialized countries. Especially in developing countries, figures from different sources vary considerably. Available data often focus on certain etiological subgroups-particularly diabetics-or on neuropathic pain $(\mathrm{NeP})$, which contributes to this variation. More epidemiological prevalence studies from the general population are required to gain a better picture on sizes of patient groups and cause patterns. To provide an overview of current prevalence data, we performed a selective literature search in PubMed, Cochrane and Google Scholar and used relevant examples along with comprehensive reviews covering the past $15+$ years identified through the use of the authors' own files. These data indicate that PN is frequent and often undiagnosed for a long time. Although diabetes is the number one cause of PN worldwide, there are various causes beyond, making it hard for physicians to gain a clear patient picture and recognize symptoms. Most clinical studies also focus on diabetic PN treatment only; thus, data comparing the treatment of $\mathrm{PN}$ of several etiologies are rare, which contributes to the lack of awareness of PN causes. In order to demonstrate that different PN subgroups can benefit from treatment with B vitamins progressively over time-regardless of underlying $\mathrm{PN}$ causes, we also present some subgroup results of a recent non-interventional study (Neurobion non-interventional; NENOIN) herein. The NENOIN study showed that treating PN of different etiologies including idiopathic neuropathy is possible with a fixed dose of neurotropic $\mathrm{B}$ vitamins. Therefore, we conclude that this is an effective treatment option for different PN subgroups from which even patients with unknown PN causes can benefit.
\end{abstract}

Keywords: Peripheral neuropathy; Neurotropic B vitamins; Etiology; Prevelance

Correspondence to: Manfaluthy Hakim, Department of Neurology, Faculty of Medicine, Universitas Indonesia -CiptoMangunkusumo National General Hospital, Jl. Salemba Raya No. 6, Jakarta-10430, Indonesia, Tel: +62 213190 3219, Fax: +62 213145 273, E-mail: hakim_dr@yahoo.com

Received: August 08, 2019; Accepted: August 26, 2019; Published: September 03, 2019

Citation: Hakim M, Kurniani N, Pinzon R, Tugasworo D, Basuki M, Haddani H, et al. (2019) A Review on Prevalence and Causes of Peripheral Neuropathy and Treatment of Different Etiologic Subgroups with Neurotropic B Vitamins. J Clin Exp Pharmacol 9: 262. doi: $10.35248 / 2161-1459.19 .9 .262$

Copyright: (C) 2019 Hakim M, et al. This is an open-access article distributed under the terms of the Creative Commons Attribution License, which permits unrestricted use, distribution, and reproduction in any medium, provided the original author and source are credited. 


\section{INTRODUCTION}

Peripheral neuropathy $(\mathrm{PN})$ is the most common disorder of the peripheral nervous system in adults, and its prevalence increases with age. Estimating its prevalence in the general population is difficult because the documentation of this disease is often poor and insufficient. Beyond that, only a few epidemiological studies on the prevalence of $\mathrm{PN}$ in the general population are available, mostly deriving from industrialized countries. Especially in developing countries, the figures vary considerably depending on the literature source. In addition, the available data often focus either on the prevalence in certain subgroups, for example patients with HIV- or cancer-induced PN, or on neuropathic pain $(\mathrm{NeP})$, which contributes to the variation [1]. It should be clear that more epidemiological studies on the prevalence of PN in the general population are required to gain a better picture of the size of the patient groups and the pattern of causes. In order to substantiate this statement and provide an overview of current prevalence data, we have therefore used various examples from the literature over the past $15+$ years.

\section{LITERATURE REVIEW}

To provide an overview of current prevalence data, we performed a selective literature search in PubMed, Cochrane and Google Scholar with the search terms 'peripheral neuropathy' AND 'prevalence' or 'peripheral neuropathy' AND 'etiology' and filtered for articles in the English language for which the full text was available. Performing the search in English language might have been a limitation because data published in other languages could not be considered. As the initial search not limited by dates yielded 781 articles, we covered the years up to 2017 by using recent comprehensive and partly systematic reviews on PN prevalence in the general population identified through the use of the authors' own files [1-6] and filtered the database searches by date (2017-2019; performed on February 14, 2019). Of the remaining 226 articles, we excluded 212 non-relevant articles based on title and abstract and searched 14 full-text publications (original articles and reviews) for additional information on $\mathrm{PN}$ prevalence in the general population. For information on the treatment of $\mathrm{PN}$, we basically used current treatment guidelines and articles from the author's own files.

\section{RESULTS}

In a review from 2015, Callaghan et al. reported that about $2-7 \%$ of the worldwide population might be affected by PN [2]. However, prevalence rates can rise noticeably if only particularly vulnerable cohorts such as elderly or diabetics are taken into account [1,3]. Hanewinckel et al. performed a comprehensive literature review in 2015 and found that, based on publications, $\mathrm{PN}$ appears to be more common in Western countries than in developing countries [1]. Nevertheless, experts believe that the prevalence is strongly biased by poor documentation and could be much higher than the published rates. Factors contributing to this gap globally and especially in developing countries are low disease awareness among both physicians and patients, the lack of simple guidance for diagnosis, physicians' lack of time for patient examination but also low awareness of patients for the need to consult a physician when experiencing symptoms [7-10]. In India, for example, $\mathrm{PN}$ is thought to be extremely underdiagnosed and-as a result of various PN causes, overlooked symptoms, inconsistent documentation, and other factors- the actual prevalence could be much higher than reported [11]. Causes of PN can generally differ between countries. In contrast to other regions of the world, leprosy, for example, is still a common cause of PN in India while the disease is considered eradicated in Western countries. Experts suspect that the particular epidemiologic situation with its multiple PN causes in India largely contributes to the fact that physicians do not have a clear picture of those who could be affected [11]. But PN is also largely underdiagnosed in other countries such as Saudi Arabia, which can be still considered a developing country despite its high per capita income. The results of a recent multi-centre cross-sectional study from a primary health care setting in Riyadh showed that about one-third of the 242 patients with type 2 diabetes mellitus (T2DM) had painful diabetic PN, but the disease was recognized by physicians only in one of them [12].

Regardless of the countries' development status, diabetes is the most common cause of PN on a worldwide base and accounts for approximately one-third of all cases $[3,5]$. Due to impaired glucose tolerance, the condition is also prevalent in pre-diabetic patients [13-15]. The prevalence of diabetes has strongly increased in recent decades-faster in low- and middle-income countries than in high-income countries. It is expected to continue rising in the future $[3,16]$ and with this development, the prevalence of $\mathrm{PN}$ will also increase.

Interestingly, diabetic $\mathrm{PN}$ seems to be more common in Caucasians than in South Asian subjects with T2DM $(54.3 \%$ versus $38.1 \%$; $\mathrm{p}=0.008$ ), which may be partially explained by factors like adiposity and height [17]. Alcoholic PN is also one of the most frequent etiologies and affects $22-66 \%$ of all chronic alcoholics [3,5]. A recent systematic review and meta-analysis including data from 87 publications found a PN prevalence of $46.3 \%$ in chronic alcohol users when considering only those cases confirmed by nerve conduction studies [6]. Other causes of $\mathrm{PN}$ include genetics, nutritional deficiencies or vitamin deficiencies, toxic substances or drugs (e.g. antiretroviral drugs), immunological processes but also infectious diseases such as leprosy (currently still the most common treatable cause of PN) or diphtheria [3-5,18]. However, in a significant number of cases, the cause of PN remains unknown and the disease is thus considered 'idiopathic'. While Landmann reported a rate of $22 \%$, Callaghan et al. assumed a proportion of $24-27 \%$ of idiopathic cases [2,5]. In recent years, chemotherapy-induced neuropathies have also gained importance due to the increasing prevalence of cancer and the use of new chemotherapeutics and targeted agents like platinum derivatives, vinca alkaloids, taxanes, and antibody-based drugs [3].

When looking at country-specific prevalence rates, it is striking that the documentation of chronic $\mathrm{NeP}$ is apparently better than that of $\mathrm{PN}$ in general. However, at the time when patients experience severe and chronic $\mathrm{NeP}$, the disease $\mathrm{PN}$ is already advanced and disabling and impairs the quality of life. Additionally, in advanced stages, $\mathrm{NeP}$ is difficult to treat with 
any of the treatment options [19]. Optimally, the diagnosis should be done in earlier stages of the disease, which is often not the case.

In the United States, the estimated prevalence of PN in the general population ranges from $6-9 \%[20,21]$ and is thus similar to the prevalence obtained from a cross-sectional, randomly selected, population-based survey in China with over 4,000 participants when summarizing the results of normoglycemic (37.2\% of subjects; PN 3.25\%), prediabetic (44\% of subjects; PN $6.29 \%$ ), and diabetic subjects (18.9\% of subjects; PN $15.12 \%$ ) [22]. In Uganda, a survey including 3,000 subjects from Mukono district found neurological diseases in 3.3\% of all participants and identified $\mathrm{PN}$ as the most prevalent neurological disorder with $46.2 \%$ (calculated overall PN prevalence $1.5 \%$ ) [23]. In contrast, another study from Uganda with $400 \mathrm{HIV}$-negative and $400 \mathrm{HIV}$-positive, antiretroviralnegative participants detected PN prevalence rates of $7 \%$ and 19\%, respectively [24]. For India, however, epidemiological studies from different regions with different ethnic and cultural background result in overall prevalence rates varying even more, from $0.05-24 \%$ [4].

As mentioned before, NeP appears to be better documented than $\mathrm{PN}$; therefore, more epidemiological studies on the prevalence of $\mathrm{NeP}$ than of $\mathrm{PN}$ are available. While Bouhassira et al. reported an overall prevalence of chronic pain with neuropathic characteristics in $6.9 \%$ of over 23,000 participants from France [25], Gajria et al. found diagnoses associated with $\mathrm{NeP}$ in only $1.3 \%$ of over 100,000 primary care electronic records from London, UK [26]. For Japan, a cross-sectional, population-based epidemiological survey with more than 5,000 respondents led to a $\mathrm{NeP}$ prevalence of 3.2\% [27]. A higher $\mathrm{NeP}$ prevalence rate of $10 \%$ [28] and a prevalence of probable $\mathrm{NeP}$ in chronic pain patients of $14.5 \%$ [29] was reported for Brazil. In addition, Dieleman et al. concluded from an Integrated Primary Care Information database that $\mathrm{NeP}$ is a rather frequent condition in the Netherlands with an annual incidence of almost $1 \%$ of the general population [30].

\section{DISCUSSION}

\section{Treatment of peripheral neuropathy}

Several treatment options for PN are available, including pharmacological, non-pharmacological, and alternative options [31-34]. Patients suffering from severe and disabling symptoms (e.g. NeP) may require guideline treatments like pregabalin, duloxetine, or gabapentin initially until the symptoms are under control [34]. These medications can symptomatically relieve $\mathrm{NeP}$; however, they do not address the underlying cause. Other options such as neurotropic B vitamins (B1, B6, and B12) do not only target the symptoms, but also improve nerve health and contribute to nerve regeneration [35]. B vitamins are commonly used for PN treatment in clinical practice worldwide, this treatment option is most suitable before the patient suffers from chronic NeP. However, co-treatment with neurotropic B vitamins is also appropriate in $\mathrm{NeP}$ patients, to ensure the restoration of nerve health [31,36]. In this way, a recent systematic review and meta-analysis suggests that high-dose neurotropic B vitamins combined with diclofenac are a more effective treatment than diclofenac monotherapy for low back pain management, including patients with $\mathrm{NeP}$ [37].

\section{Treating peripheral neuropathy of different etiologies}

Given the high prevalence of the disease in the general population and the various causes of $\mathrm{PN}$, we are particularly interested in treating $\mathrm{PN}$ in different etiologic subgroups. In general, we have noticed a lack of clinical data on this aspect because studies rarely investigate different etiologic subgroups. As diabetes is the most common cause of PN [3,5], patients with diabetic PN are also the best-documented subgroup in terms of treatment. One recent approach to fill this data gap is the Peripheral Neuropathy Research Registry (PNRR; https:// thepnrr.org/), which focuses on idiopathic, diabetic, HIVrelated, and chemotherapy-induced $\mathrm{PN}$. The registry has the overall goal of finding disease-altering treatments and better symptom relief for patients [38]. As stated before, other etiologic subgroups than diabetic patients still appear less homogenous and are often not well-known to physicians [11]. Accordingly, many patients with $\mathrm{PN}$ are not recognized and/or the doctors do not know how to treat them.

We have recently published the results of a prospective, openlabel, multi-center, single-arm observational study in Indonesia on 411 subjects with PN of different etiologies who were treated with a fixed-dose combination of high-dose vitamin B1 (100 $\mathrm{mg})$, B6 (100 mg), and B12 (5 mg) for 12 weeks [39]. The socalled NENOIN (Neurobion non-interventional) study revealed that this treatment is effective and well-tolerated and improves PN symptoms significantly and progressively over time. In total, the study included 104 patients with diabetic PN, 44 with carpal tunnel syndrome, 112 with idiopathic PN, 25 with other types of $\mathrm{PN}$, and 126 with combinations of different etiologies. In addition to the primary publication [39], some results on the etiologic subgroups have been published in a local Indonesian journal [40]. However, the article is not freely available online, but we believe that the results are of interest to a wider audience that includes readers from other countries than Indonesia. Hence, we recap some of the already published subgroup results and also present other unpublished subgroup results to demonstrate that $\mathrm{PN}$ can be treated with B vitamins-regardless of etiologies.

PN symptoms in the subgroups were measured using Total Symptom Score (TSS; primary outcome measure) and Visual Analogue Scale (VAS; secondary outcome measure) score, as previously described in more detail $[39,40]$. As shown in Figure 1 , the mean TSS improved significantly from visit 1 (baseline) to visit 5 (day 90) in all of the studied subgroups. The improvements were not only observed for TSS Total, but also for all individually recorded symptoms (stabbing pain, burning pain, paresthesia, and numbness). Except for the symptom 'burning pain' in the subgroup 'other', all differences from baseline were statistically significant. The results for the mean VAS (Figure 2) were consistent with the TSS results. Again, all scores in all subgroups improved clearly for all symptoms (pain, burning, paresthesia, numbness, and tingling) with documented data. Differences from baseline were statistically significant for all 
except the symptom 'paresthesia' in the subgroup 'combination',

for which only one patient's data were available at visit 5 .

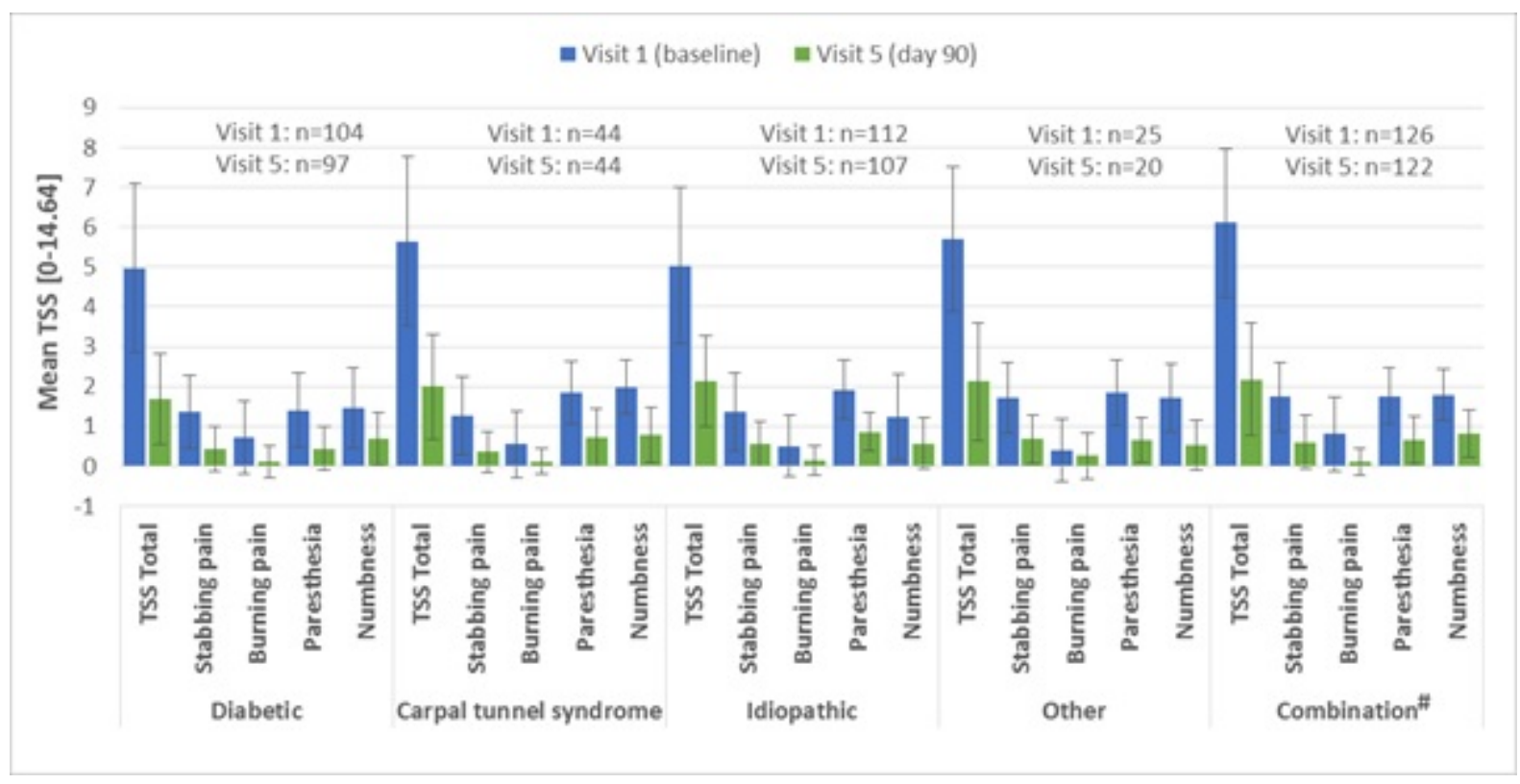

Figure 1: Mean TSS scores in subgroups over time. Symptom improvement (mean TSS) from visit 1 (baseline) to visit 5 (day 90 ) by neuropathy type. Standard deviation shown as error bars. TSS=Total Symptom Score; \#neuropathy due to combinations of different etiologies. Differences between visit 1 and visit 5 were highly significant with $\mathrm{p}<0.0001$ in all cases except carpal tunnel syndrome/burning pain ( $\mathrm{p}=0.0004)$, other/burning pain ( $\mathrm{p}=0.125)$, and other/numbness $(\mathrm{p}=0.0002)$.

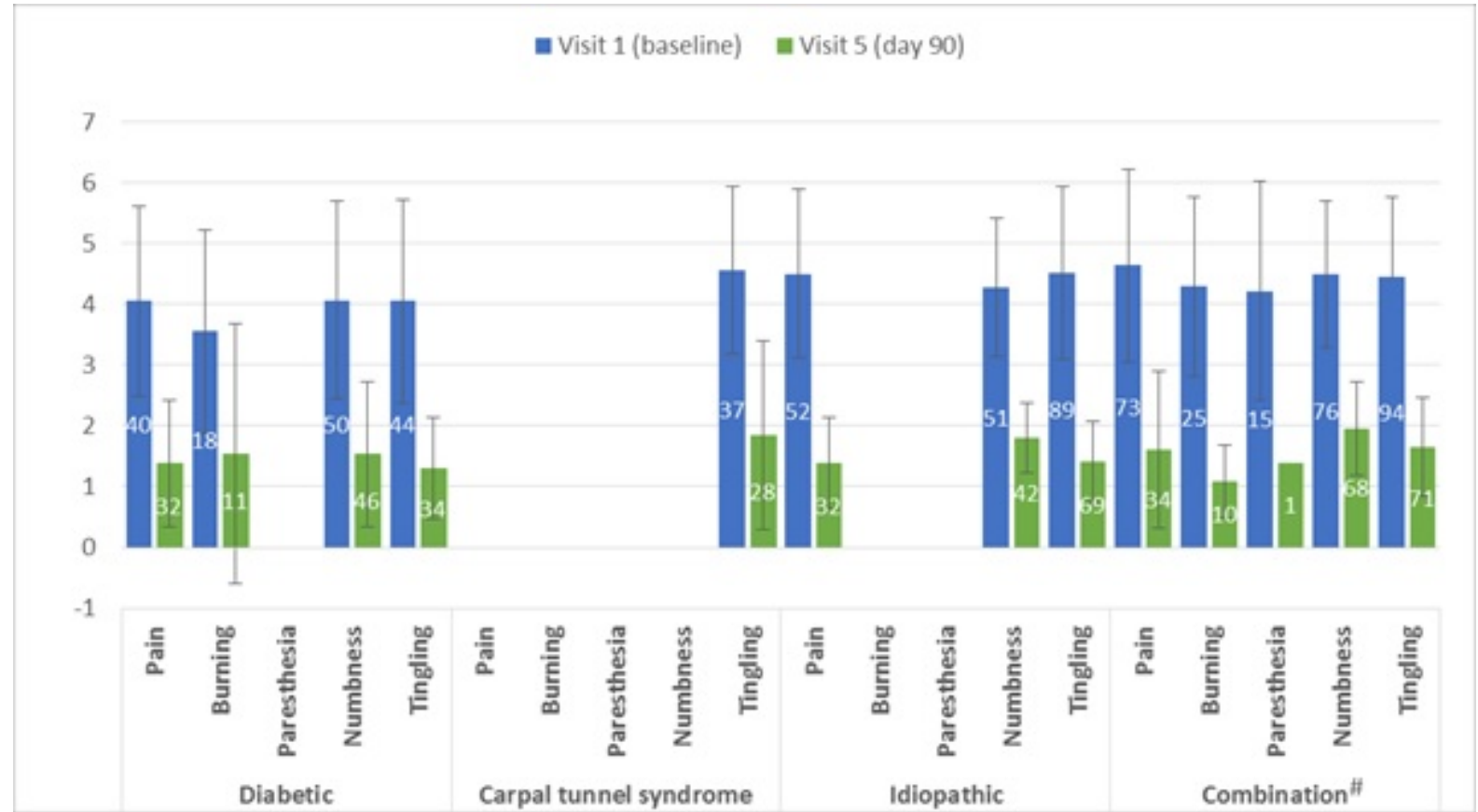

Figure 2: Mean VAS scores in subgroups over time. Symptom improvement (mean VAS score) from visit 1 (baseline) to visit 5 (day 90 ) by neuropathy type. Numbers in columns represent patient numbers. Standard deviation shown as error bars. VAS=Visual Analogue Scale; \#neuropathy due to combinations of different etiologies. Differences between visit 1 and visit 5 were highly significant with $\mathrm{p}<0.0001$ in all cases except diabetic/burning $(\mathrm{p}=0.0078)$, combination/burning $(\mathrm{p}=0.0039)$, and combination/paresthesia $(\mathrm{p}=1)$. No data available for neuropathy type 'other'.

These trends were also reflected by the mean percentage reductions of both scores over time. The mean TSS percentage reduction from baseline was clinically relevant from visit 2 onwards until visit 5 for TSS Total and for all individual symptoms (stabbing pain, burning pain, paresthesia, and numbness) in all subgroups and increased progressively over time (Figure 3) [40]. 


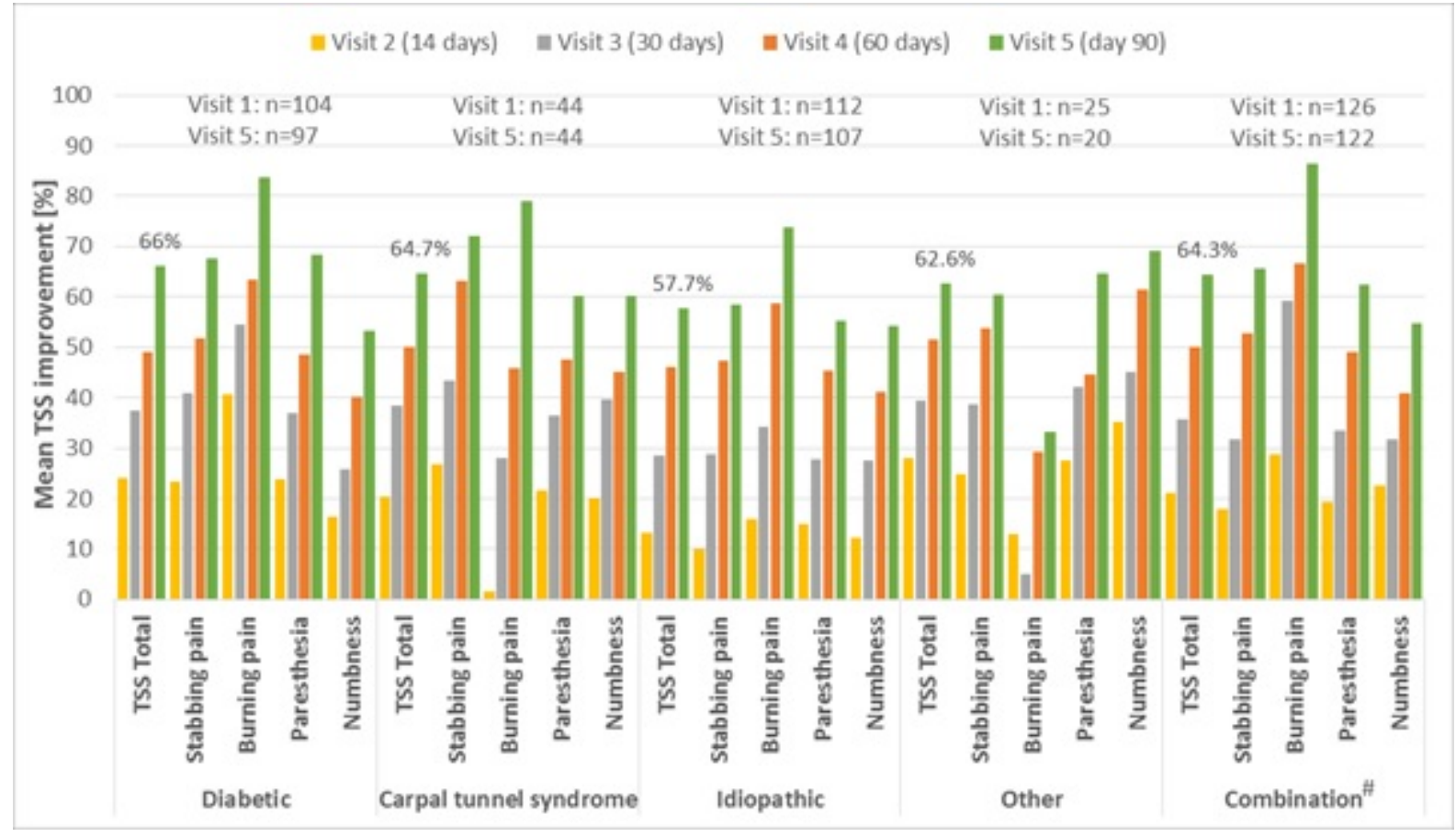

Figure 3: Mean TSS percentage improvement in subgroups over time. Symptom improvement (mean TSS percentage reduction from baseline) over time by neuropathy type. TSS=Total Symptom Score; \#neuropathy due to combinations of different etiologies. Differences between visit 1 and 5 were highly significant with $\mathrm{p}<0.0001$ in all cases except carpal tunnel syndrome/burning pain $(\mathrm{p}=0.0004)$, other/burning pain ( $\mathrm{p}=0.125)$, and other/ numbness $(\mathrm{p}=0.0002)$.

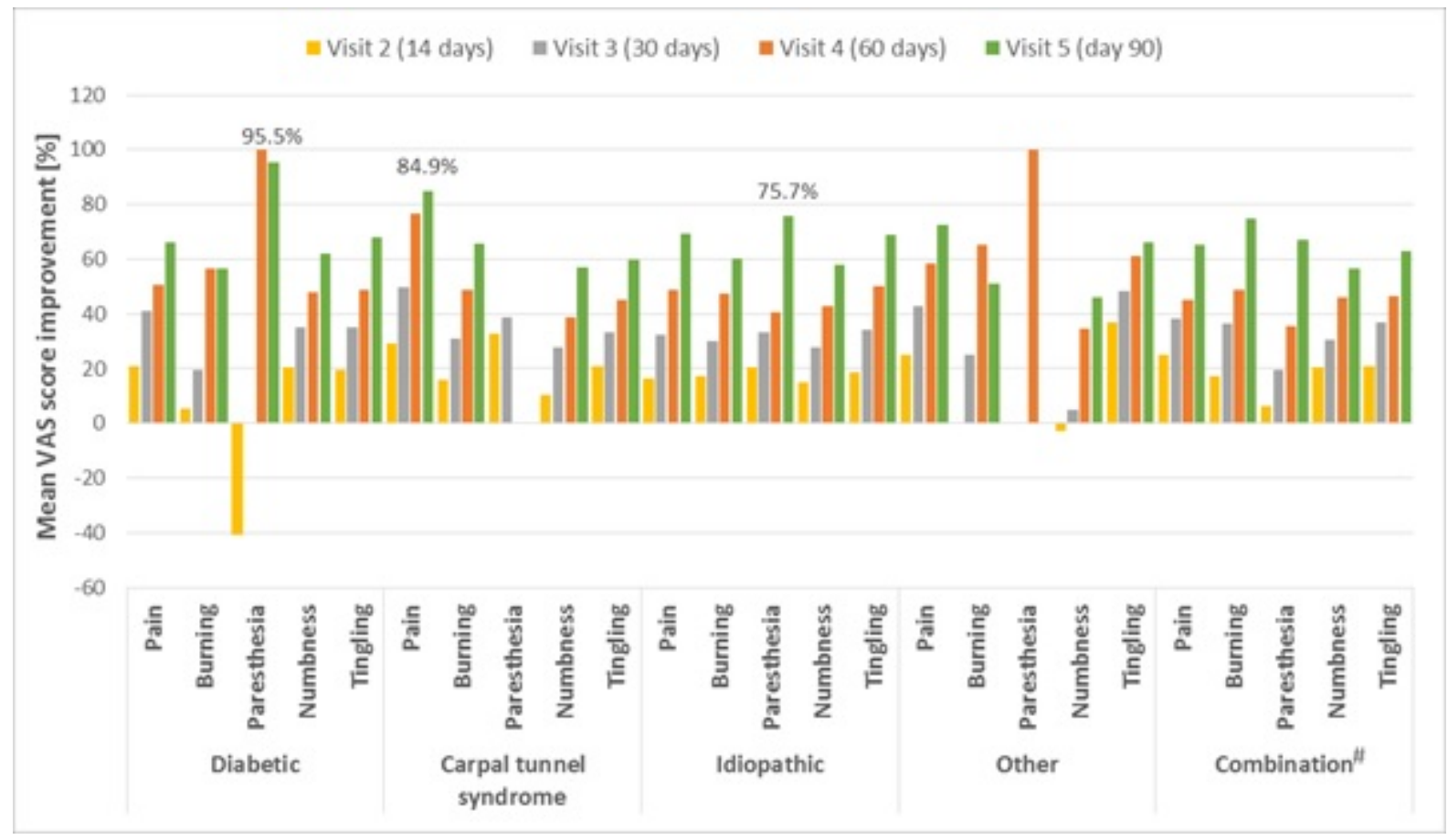

Figure 4: Mean VAS percentage improvement in subgroups over time. Symptom improvement (mean VAS score percentage reduction from baseline) over time by neuropathy type. VAS=Visual Analogue Scale; \#neuropathy due to combinations of different etiologies. Differences between visit 1 and visit 5 were highly significant with $p<0.0001$ in all cases except diabetic/burning ( $=0.0078)$, combination/burning ( $p=0.0039)$, and combination/ paresthesia $(\mathrm{p}=1)$. No data available for neuropathy type 'other'.

In the diabetic subgroup, the mean percentage reduction of TSS Total from baseline to visit 5 was $66.0 \%$, while it was $64.7 \%$ for carpal tunnel syndrome, $57.7 \%$ for idiopathic neuropathy, $62.6 \%$ for other neuropathy types, and $64.3 \%$ for combinations of different neuropathy types. The mean percentage reduction in VAS for pain, burning, paresthesia, numbness, and tingling from baseline to visit 5 also indicated clinically meaningful symptom improvements in all neuropathic subgroups (Figure 4) [40]. However, an increase was observed at visit 2 for 'paresthesia' in 'diabetic PN' and for 'numbness' in 'other PN'. 
The three highest mean percentage reductions of VAS from baseline to visit 5 were detected for paresthesia in diabetic subjects $(95.5 \%)$, followed by pain in carpal tunnel syndrome (84.9\%), and paresthesia in idiopathic PN (75.7\%).

\section{CONCLUSION}

In this review, we have outlined that the documentation of PN prevalence in the general population is very poor globally and that sufficient data from large epidemiological studies are lacking. However, available PN prevalences from different countries indicate that $\mathrm{PN}$ is a frequent disease and often remains undiagnosed for an extended period. In addition, PN can have a variety of causes beyond diabetes, which makes it difficult for physicians to gain a clear patient picture and recognize (early) symptoms. On a worldwide base, diabetes is the number one cause, followed by idiopathic PN. Most clinical studies, therefore, focus on the treatment of diabetic PN. Accordingly, data from studies comparing the treatment of PN of several etiologies are rare. The NENOIN study showed that treating PN of different etiologies including idiopathic neuropathy is possible and symptoms improved progressively over time in all included subgroups. We conclude that a fixeddose combination of high-dose vitamin B1, B6, and B12 is an effective treatment option for different $\mathrm{PN}$ subgroups regardless of the underlying $\mathrm{PN}$ cause and that even patients with unknown causes can benefit from it.

\section{ACKNOWLEDGEMENT}

Medical writing assistance was provided by Dittmann Medical Writing (Hamburg, Germany), the work was funded by P\&G Health Germany GmbH, Darmstadt, Germany. The authors are fully responsible for all content and editorial decisions for this manuscript.

\section{CONFLICT OF INTEREST}

The authors do not have any conflicts of interest to declare.

\section{REFERENCES}

1. Hanewinckel R, Van Oijen M, Ikram MA, Van Doorn PA. The epidemiology and risk factors of chronic polyneuropathy. Eur. J. Epidemiol. 2016;31:5-20.

2. Callaghan BC, Price RS, Feldman EL. Distal symmetric polyneuropathy: A review. JAMA. 2015;314:2172-2181.

3. Sommer C, Geber C, Young P, Forst R, Birklein F, Schoser B. Polyneuropathies. Dtsch Arztebl Int. 2018;115:83-90.

4. Trivedi S, Pandit A, Ganguly G, Das SK. Epidemiology of Peripheral Neuropathy: An Indian Perspective. Ann Indian Acad Neurol. 2017;20:173-184.

5. Landmann G. Diagnostik und Therapie der schmerzhaften Polyneuropathie. Psychiatr Neurol. 2012;5:13-16.

6. Julian T, Glascow N, Syeed R, Zis P. Alcohol-related peripheral neuropathy: A systematic review and meta-analysis. J Neurol. 2018. Epub ahead of print.

7. Tesfaye S, Vileikyte L, Rayman G, Sindrup SH, Perkins BA, Baconja $\mathrm{M}$, et al. Painful diabetic peripheral neuropathy: consensus recommendations on diagnosis, assessment and management. Diabetes Metab Res. Rev. 2011;27:629-638.
8. Sadosky A, Hopper J, Parsons B. Painful diabetic peripheral neuropathy: results of a survey characterizing the perspectives and misperceptions of patients and healthcare practitioners. Patient. 2014;7:107-114.

9. Malik RA, Aldinc E, Chan SP, Deerochanawong C, Hwu CM, Rosales RL, et al. Perceptions of painful diabetic peripheral neuropathy in South-East Asia: Results from patient and physician surveys. Adv Ther. 2017;34:1426-1437.

10. Herman WH, Kennedy L. Underdiagnosis of peripheral neuropathy in type 2 diabetes. Diabetes Care. 2005;28:1480-1481.

11. Srinivasan A, Paranjothi S, Bhattacharyya K, Maji D, Hazra D, Talwalkar $\mathrm{P}$, et al. Consensus recommendation for the management of peripheral neuropathy in India. J Indian Med Assoc. 2018;116:45-55.

12. Algeffari MA. Painful diabetic Peripheral neuropathy among Saudi diabetic patients is common but under-recognized: Multicenter cross-sectional study at primary health care setting. J Family Community Med. 2018;25:43-47.

13. Lee CC, Perkins BA, Kayaniyil S, Harris SB, Retnakaran R, Gerstein HC, et al. Peripheral neuropathy and nerve dysfunction in individuals at high risk for Type 2 diabetes: The PROMISE Cohort. Diabetes Care. 2015;38:793-800.

14. Stino AM, Smith AG. Peripheral neuropathy in prediabetes and the metabolic syndrome. J Diabetes Investig. 2017;8:646-655.

15. Ziegler D, Rathmann W, Dickhaus T, Meisinger C, Mielck A. Neuropathic pain in diabetes, prediabetes and normal glucose tolerance: the MONICA/KORA Augsburg Surveys S2 and S3. Pain Med 2009; 10:393-400.

16. NCD Risk Factor Collaboration (NCD-RisC). Worldwide trends in diabetes since 1980: A pooled analysis of 751 population-based studies with 4.4 million participants. Lancet. 2016;387:15130-1530.

17. Tahrani AA, Altaf QA, Piya MK, Barnett AH. Peripheral and autonomic neuropathy in South Asians and White Caucasians with Type 2 diabetes mellitus: Possible explanations for epidemiological differences. J Diabetes Res 2017;2017:1273789.

18. https://www.who.int/mental_health/neurology/neurodiso/en/

19. Nix WA. Muscles, Nerves, and Pain. Springer-Verlag Berlin, Heidelberg (Germany) 2017.

20. www.foundationforpn.org/what-is-peripheral-neuropathy/types-riskfactors/

21. https://www.ninds.nih.gov/Disorders/Patient-Caregiver-Education/ Fact-Sheets/Peripheral-Neuropathy-Fact-Sheet

22. Callaghan BC, Gao L, Li Y, Zhou X, Reynolds E, Banerjee M, et al. Diabetes and obesity are the main metabolic drivers of peripheral neuropathy. Ann Clin Transl Neurol. 2018;5:397-405.

23. Kaddumukasa M, Mugenyi L, Kaddumukasa MN, Ddumba E, Devereaux M, Furlan A, et al. Prevalence and incidence of neurological disorders among adult Ugandans in rural and urban Mukono district: A cross-sectional study. BMC Neurol. 2016; 16:227.

24. Saylor D, Nakigozi G, Nakasujja N, Robertson K, Gray RH, Wawer MJ, et al. Peripheral neuropathy in HIV-infected and uninfected patients in Rakai, Uganda. Neurol. 2017;89:485-491.

25. Bouhassira D, Lanteri-Minet M, Attal N, Laurent B, Touboul C. Prevalence of chronic pain with neuropathic characteristics in the general population. Pain. 2008;136:380-387.

26. Gajria C, Murray J, Birger R, Banarsee R, Bennett DL, Tan K, et al. Identification of patients with neuropathic pain using electronic primary care records. Inform Prim Care. 2011;19:83-90.

27. Inoue $S$, Taguchi $T$, Yamashita $T$, Nakamura M, Ushida $T$. The prevalence and impact of chronic neuropathic pain on daily and 
social life: A nationwide study in a Japanese population. Eur J Pain. 2017;21:727-737.

28. de Moraes Vieira EB, Garcia JBS, da Silva AAM, Mualem Araujo RLT, Jansen RCS. Prevalence, characteristics, and factors associated with chronic pain with and without neuropathic characteristics in Sao Luis, Brazil. J Pain Symptom Manage. 2012;44:239-251.

29. Udall M, Kudel I, Cappelleri JC, Sadosky A, King-Concialdi K, Parsons B, et al. Epidemiology of physician-diagnosed neuropathic pain in Brazil. J Pain Res. 2019;12:243-253.

30. Dieleman JP, Kerklaan J, Huygen FJPM, Bouma PAD, Sturkenboom MCJM. Incidence rates and treatment of neuropathic pain conditions in the general population. Pain. 2008; 137:681-688.

31. Head KA. Peripheral neuropathy: pathogenic mechanisms and alternative therapies. Altern Med Rev. 2006;11:294-329.

32. Finnerup NB, Attal N, Haroutounian S, McNicol E, Baron R, Dworkin RH, et al. Pharmacotherapy for neuropathic pain in adults: A systematic review and meta-analysis. Lancet. Neurol. 2015; 14:162-173.

33. Elmofty DH, Anitescu M, Buvanendran A. Best practices in the treatment of neuropathic pain. Pain Manag. 2013;3:475-483.

34. Pop-Busui R, Boulton AJM, Feldman EL, Bril V, Freeman R, Malik RA, et al. Diabetic neuropathy: A position statement by the American Diabetes Association. Diabetes Care. 2017;40:136-154.
35. Calderón-Ospina C, Nava-Mesa M, B Vitamins in the nervous system: Current knowledge of the biochemical modes of action and synergies of thiamine, pyridoxine and cobalamin. CNS Neurosci. Ther. 2019. In press.

36. Geller M, Oliveira L, Nigri R, Mezitis SG, Ribeiro MG, Da Fonseca AS, et al. B Vitamins for neuropathy and neuropathic pain. Vitam Miner. 2017;6: 2.

37. Calderón-Ospina C, Nava-Mesa M. Effect of combined diclofenac and $\mathrm{B}$ vitamins (thiamine, pyridoxine and cyanocobalamin) for low back pain management: A systematic review and meta-analysis. Pain Med. 2019. In press.

38. Thomas S, Ajroud-Driss S, Dimachkie MM, Gibbons C, Freeman R, Simpson DM, et al. Peripheral Neuropathy Research Registry: A prospective cohort. J Peripher Nerv Syst. 2019. Epub ahead of print.

39. Hakim M, Kurniani N, Pinzon RT, Tugasworo D, Basuki M, Haddani $H$, et al. Management of peripheral neuropathy symptoms with a fixed dose combination of high-dose vitamin B1, B6 and B12: A 12-week prospective non-interventional study in Indonesia. Asian J Med Sci. 2018;9:32-40.

40. Hakim M, Kurniani N, Pinzon RT, Tugasworo D, Basuki M, Haddani H, et al. Vitamin B1, B6, and B12 combination in the management of peripheral neuropathy symptoms in Indonesia: $\mathrm{A}$ sub group analysis of NENOIN Study. J Kedokt Indones. 2018;4:43-49. 